\title{
Malignant hyperthermia and dantrolene sodium
}

\author{
Ha Jung Kim, Won Uk Koh, Jae Moon Choi, Young Jin Ro, and \\ Hong Seuk Yang
}

Department of Anesthesiology and Pain Medicine, Asan Medical Center, University of Ulsan College of Medicine, Seoul, Korea

Recently, there was a case report of malignant hyperthermia in Korea. The patient was treated with conventional methods including dantrolene, but the patient's condition became aggravated, requiring the application of an extracorporeal membrane oxygenator (ECMO) to support cardiopulmonary resuscitation [1]. However, if the patient had been treated by prompt administration of dantrolene (i.e., within 20 minutes), we wonder how the patient's clinical course may have progressed.

According to the European Malignant Hyperthermia Group guidelines for management of malignant hyperthermia, at least 36 vials of $20 \mathrm{mg}$ dantrolene should be prepared within 10-15 minutes to effectively treat the condition. However, dantrolene is expensive and has a short life span; thus, routine preparation of dantrolene may not be cost effective [2]. In a previous report, it was noted that many hospitals were not prepared to provide the recommended dose of 36 vials of dantrolene [3]. Although the preparation of 36 vials is not necessarily cost-effective, preparation of the first dose is recommended to prevent serious complications involving reduced mortality, as well as to provide the anesthesiologist with time to prepare the second dose of dantrolene [4].

Therefore, it is necessary to reorganize the current system, in which dantrolene is prepared only in single base hospitals in each region; we propose that the system should be modified to ensure preparation of the first dose of dantrolene such that it can be readily administered in each hospital. We expect that this would enable the first dose of dantrolene to be administered in a much faster time interval than in the current system; this could save patients by reducing associated mortality and morbidity. In addition, patients who express some symptoms and signs that are similar to malignant hyperthermia may not be confirmed as cases of malignant hyperthermia. Therefore, an additional system should be prepared to enable prompt patient transfer to the malignant hyperthermia center; moreover, the caffeine-halothane contracture test and gene test should be available, which can be used for diagnosis and further assistance of patients and their families. This would facilitate prevention of malignant hyperthermia in the future and provide necessary information to the medical providers.

We think that a properly equipped malignant hyperthermia center is essential to confirm diagnosis and support affected patients in Korea.

\section{ORCID}

Ha Jung Kim, https://orcid.org/0000-0002-1759-4592

Won Uk Koh, https://orcid.org/0000-0003-4881-1884

Jae Moon Choi, https://orcid.org/0000-0002-1161-6586

Young Jin Ro, https://orcid.org/0000-0003-4024-685X

Hong Seuk Yang, https://orcid.org/0000-0003-2023-8705

Corresponding author: Hong Seuk Yang, M.D., Ph.D.

Department of Anesthesiology and Pain Medicine, Asan Medical Center, University of Ulsan College of Medicine, 88 Olympic-ro 43-gil, Songpa-gu, Seoul 05505, Korea

Tel: 82-2-3010-3865, Fax: 82-2-470-1363, Email: hsyang@amc.seoul.kr

ORCID: https://orcid.org/0000-0003-2023-8705

Received: May 24, 2018. Accepted: June 1, 2018.

Korean J Anesthesiol 2019 February 72(1): 78-79

https://doi.org/10.4097/kja.d.18.00139

(c) This is an open-access article distributed under the terms of the Creative Commons Attribution Non-Commercial License (http://creativecommons.org/ licenses/by-nc/4.0/), which permits unrestricted non-commercial use, distribution, and reproduction in any medium, provided the original work is properly cited. 


\section{References}

1. Huh H, Jung JS, Park SJ, Park MK, Lim CH, Yoon SZ. Successful early application of extracorporeal membrane oxygenation to support cardiopulmonary resuscitation for a patient suffering from severe malignant hyperthermia and cardiac arrest: a case report. Korean J Anesthesiol 2017; 70: 345-9.

2. Aderibigbe T, Lang BH, Rosenberg H, Chen Q, Li G. Cost-effectiveness analysis of stocking dantrolene in ambulatory surgery centers for the treatment of malignant hyperthermia. Anesthesiology 2014; 120: 1333-8.

3. Pfenninger E, Heiderich S, Klingler W. Stocks of dantrolene in anesthesia and intensive care units in Germany : nationwide online survey with 1673 participants. Anaesthesist 2017; 66: 773-81.

4. Yip WH, Mingi CL, Ooi SJ, Chen SC, Chiang YY. A survey for prevention and treatment of malignant hyperthermia in Taiwan. Acta Anaesthesiol Taiwan 2004; 42: 147-51. 